\title{
Os poderes dos seguranças particulares no policiamento das propriedades privadas de massa*
}

Cleber da Silva Lopes**

Resumo: A segunda metade do século XX testemunhou uma mudança importante na organização do espaço urbano e do controle social formal. Parte das interações sociais que antes ocorriam em espaços públicos policiados pela polícia deslocaram-se para propriedades privadas de massa policiadas por forças de segurança privada. Diante dessa realidade, o artigo analisa os fundamentos e os limites de alguns dos poderes legais mais usados no policiamento dos usuários dessas propriedades: as obstruções de entrada, as expulsões e as revistas. A pesquisa está baseada no estudo empírico de normas estatais e na análise quantitativa e qualitativa de 216 processos julgados pelo Tribunal de Justiça de São Paulo e pelo Tribunal de Justiça do Paraná relacionados ao uso desses poderes. Os resultados mostram que os seguranças que policiam os indivíduos nas propriedades de massa detêm poderes legais mais amplos do que os policiais que policiam os cidadãos nos espaços públicos convencionais. As consequências desse achado são discutidas.

Palavras-chave: Policiamento. Segurança privada. Propriedades privadas de massa. Poderes legais. Arbitrariedades.

The powers of private security in policing private properties for collective use

Abstract: The second half of the twentieth century witnessed a major change in the organization of urban space and formal social control. An important part of social interactions that had previously occurred in public spaces policed by the police moved to mass private properties policed by private security forces. Faced with this reality, this paper analyzes the foundations and limits of some legal powers used in policing of mass private properties' users: the deny from entries, the ejections and the searches. The research is based on the empirical study of state norms and on the quantitative and qualitative analysis of 216 cases judged by the Tribunal de Justiça de São Paulo and the Tribunal de Justiça do Paraná related to the use of these powers. The results show that the security guards in mass private properties have broader powers than police officers in public spaces. The consequences of this finding are discussed.

Keywords: Policing. Private security. Mass private property. Legal powers. Abuses.

\author{
* Trabalho \\ resultante da \\ pesquisa "Os poderes \\ da segurança \\ privada: um estudo \\ exploratório \\ sobre a atuação \\ dos profissionais \\ regulares de \\ segurança privada \\ nas cidades de São \\ Paulo e Londrina", \\ financiada pelo \\ Conselho Nacional \\ de Desenvolvimento \\ Científico e \\ Tecnológico (CNPq) \\ - Chamada Universal \\ 2014, Processo: \\ 459514/2014-8.

** Cleber da Silva
Lopes é professor
adjunto do
Departamento de
Ciências Sociais e
do Programa de
Pós-Graduação
em Sociologia
da Universidade
Estadual de Londrina
(UEL), coordenador
do Laboratório
de Estudos Sobre
Governança da
Segurança (LEGS),
Londrina, Paraná,
Brasil.
Orcid: 0000-0002-
2197-159X.
<clopes@uel.br>. \\ <clopes@uel.br>.
}




\section{Introdução}

1. Opto pelo termo propriedade privada de massa (mass private property) de Clifford Shearing e Philip Stenning (1981), que foram os primeiros a analisar as mudanças no espaço urbano e no controle social formal abordadas neste trabalho.
O s estudos sobre controle social formal têm sido dominados por análises sobre o policiamento realizado por agentes estatais nos espaços públicos de áreas urbanas. Esse foco reflete, em grande medida, o fato de que predominou nos últimos dois séculos uma identificação entre espaço público, ordem pública e polícia. Os espaços públicos são tipicamente entendidos como espaços onde os membros de um Estado territorial podem circular e se expressar livremente. Seu uso é regulado por normas estatais que definem quais atividades e comportamentos devem ser permitidos e quais devem ser proscritos. Essas normas conformam uma ordem pública cuja principal fiadora é a polícia. A existência dessa realidade indica o quão bem-sucedido o Estado moderno foi em incorporar domínios territoriais concorrentes e construir instituições capazes de assegurar o controle das populações que neles circulam.

Essa identificação histórica entre espaço público, ordem pública e polícia foi parcialmente rompida na segunda metade do século XX com a emergência e proliferação de propriedades privadas de massa tais como as grandes plantas industriais, os condomínios de escritórios, os condomínios residenciais, os terminais de transporte, os campi universitários, os centros de eventos, os parques de diversão, as arenas esportivas, os shopping centers e outras que oferecem serviços e entretenimento ao público. Esses espaços vêm sendo chamados de maneiras diversas - "propriedades privadas de massa" (Shearing \& Stenning, 1981), "espaços comunais" (Kempa, Stenning \& Wood, 2004), "enclaves fortificados" (Caldeira, 2003), "espaços híbridos" (Kempa et alii, 1999) -, mas há concordância quanto ao fato de que a sua disseminação altera a natureza da organização urbana e do controle social formal ${ }^{1}$. As áreas das propriedades privadas de massa não são públicas tais como os espaços públicos convencionais, isto é, não são áreas onde todos os cidadãos têm o direito de acessar e circular livremente. São áreas cujo acesso e uso são regulados por seus possuidores e por forças de segurança privada. Assim, com a proliferação desses novos espaços, parte expressiva das interações sociais que antes se desenrolava nos espaços públicos sob o controle da polícia passa agora a ocorrer em espaços juridicamente privados sob o controle de seguranças particulares que executam um tipo de policiamento que mobiliza poderes distintos dos poderes da polícia.

Enquanto os poderes detidos pelos agentes estatais responsáveis por policiar os espaços públicos têm sido amplamente pesquisados pelas ciências sociais brasileiras, os poderes dos seguranças particulares para policiar as propriedades privadas de massa foram pouco estudados. Essa lacuna pode ser parcialmente explicada pela 
forte identificação conceitual existente na produção nacional sobre "segurança pública" entre polícia e policiamento. Como notaram Jacqueline Muniz e Eduardo Paes-Machado (2010), André Zanetic (2012) e Cleber Lopes (2013), a polícia é apenas uma das instituições que fazem policiamento, que é uma atividade de controle social instrumental baseada em vigilância e ameaça/uso de força física também executada por atores não estatais no âmbito do mercado ou de comunidades.

Este artigo analisa os principais poderes legais disponíveis aos seguranças particulares para o policiamento de usuários de propriedades privadas de massa: as obstruções de entrada, as expulsões e as revistas. Seguranças que atuam em propriedades de massa também abordam usuários, realizam prisões em flagrante e usam força física, todavia, esses poderes não são particulares aos seguranças e estão disponíveis a quaisquer cidadãos. Essa é a razão pela qual Mark Button (2007) chamou os poderes de obstrução, expulsão e revista de "ferramentas legais seletivas" e os poderes de questionar, prender e usar força física de "ferramentas legais universais". Ao levar em consideração essa divisão analítica e o fato de as ferramentas universais disponíveis aos seguranças particulares terem sido abordadas em outro trabalho (Lopes, 2018), o objetivo deste artigo é analisar os fundamentos e os limites das "ferramentas legais seletivas" usadas pelos seguranças para o policiamento dos usuários das propriedades de massa². Quais são as bases legais que autorizam seguranças particulares a realizar obstruções de entrada, expulsões e revistas em usuários de propriedades de massa? Quais são os limites impostos pelo Estado para o uso de tais poderes? Essas questões serão respondidas por meio do estudo das normas estatais que incidem sobre a atuação de seguranças particulares e da análise de uma amostra aleatória de litígios judiciais envolvendo o uso de obstruções, expulsões ou revistas realizadas em usuários de propriedades de massa. A amostra é formada por 216 acórdãos julgados no Tribunal de Justiça de São Paulo (TJSP) e no Tribunal de Justiça do Paraná (TJPR), analisados por meio de técnicas quantitativas (estatística descritiva) e qualitativas (análise de conteúdo).

Analisar os fundamentos e os limites dos poderes de obstrução de entrada, expulsão e revista é fundamental para entendermos melhor as condições que tornam possível o policiamento privado das propriedades de massa. Boa parte das interações sociais se desenvolvem nos dias de hoje no interior dessas propriedades e compreender as ferramentas legais usadas no policiamento desses espaços é contribuir para o entendimento do modo como o controle social formal vem sendo exercido das sociedades contemporâneas. Esse tipo de análise também é importante para uma melhor compreensão do grau de autonomia concedido pelo Estado aos atores não estatais responsáveis pela definição e implementação da ordem nas propriedades de massa. 
Além desta introdução, o artigo está organizado em mais quatro seções e considerações finais. A primeira seção discute o contexto espacial e normativo que torna possível aos possuidores de propriedades regular o acesso e o uso de suas posses por meio de seguranças particulares. Essa seção também discute como a disseminação das propriedades privadas de massa impacta a natureza da própria governança, que, para alguns, é hoje em grande medida realizada por autoridades corporativas que atuam como governos privados que definem a natureza da ordem e o modo como ela deve ser mantida. A segunda seção apresenta os procedimentos de coleta de dados e a metodologia usada no estudo das decisões judiciais. A seção seguinte expõe os resultados da análise quantitativa e qualitativa das decisões judiciais. A quarta seção discute os resultados à luz de questões presentes na literatura e a partir de uma breve comparação entre os poderes disponíveis aos policiais nos espaços públicos e os poderes disponíveis aos seguranças nas propriedades privadas de massa. $O$ artigo finaliza com algumas breves considerações sobre os desafios postos para a regulação dos poderes de exclusão dos seguranças que atuam em espaços quase públicos como os shopping centers.

\section{Os direitos de propriedade e as ferramentas legais seletivas da segurança privada}

Desde o final da década de 1970 sociólogos e criminólogos vêm demonstrando por meio de estudos realizados em países majoritariamente anglo saxões - Canadá (Rigakos \& Greener, 2000; Stenning \& Shearing, 1979), Estados Unidos (Stenning, 2000), Austrália (Sarre, 2003) e Inglaterra/País de Gales (Button, 2007) - que a principal fonte de poder e legitimidade para a ação dos seguranças particulares não deriva de leis específicas que conferem poderes excepcionais a eles. Enquanto as autoridades estatais que integram os sistemas públicos de justiça detêm poderes especiais concedidos por normas que foram debatidas e aprovadas nos parlamentos com esse propósito, os seguranças particulares derivam sua autoridade de fontes legais que não foram desenhadas com o intuito de conceder poder a eles e que raramente são objeto de debate público: leis civis e criminais que garantem a todos os cidadãos o direito de questionar, prender em flagrante delito e usar força física em legítima defesa própria ou de terceiros - as chamadas ferramentas universais; e leis trabalhista, contratuais e de propriedade que conferem aos seguranças a capacidade de realizar revistas, obstruir entradas e expulsar pessoas dos espaços onde atuam - as chamadas "ferramentas seletivas" (Button, 2007).

A principal base normativa das ferramentas legais seletivas deriva da estreita associação entre propriedade privada e segurança privada. Shearing e Stenning (1981; 1983) foram pioneiros na identificação desse fenômeno na esfera anglo-saxônica. 
Segundo os autores, os poderes dos seguranças para restringir acessos, efetuar revistas e expulsar pessoas de determinados espaços derivam dos direitos que os detentores de propriedades têm de regular o acesso e uso de suas posses. Esses direitos são delegados aos seguranças particulares, que, como representantes dos detentores de propriedades, acabariam desfrutando de poderes superiores aos dos cidadãos comuns e sujeitos a controles legais menos estreitos do que os existentes para os policiais.

Os direitos que os detentores de propriedades têm de regular o acesso e o uso de suas posses têm origem na ideia de que as sociedades liberais devem criar e manter espaços privados destinados a garantir a privacidade dos indivíduos e o direito de eles efetuarem escolhas livres da interferência do Estado e de terceiros. A realização histórica dessa ideia ocorreu por meio da identificação entre propriedade privada e espaço privado. A instituição legal da propriedade privada ocorreu, na maioria das sociedades ocidentais, a partir do século XVIII por meio do desenvolvimento de garantias constitucionais contra intrusões externas no direito de propriedade, principalmente por agentes estatais. Essas garantias conferiram aos detentores de propriedades o direito de negar o acesso e a permanência em suas posses, bem como o direito de dispor sobre como se comportar nelas. Foram assim criados espaços privados para que os indivíduos pudessem usufruir de privacidade e liberdade. Como consequência, na maioria das democracias liberais uma propriedade privada somente pode ser acessada caso haja a autorização de seu responsável legal ou em situações excepcionais previstas em lei - normalmente diante da ocorrência de crime ou via mandado judicial. Essa autorização ocorre sob bases arbitrárias e pode ser negada a qualquer um e por qualquer motivo - excetuada as situações previstas em lei. As pessoas também podem definir as regras de comportamento a serem seguidas no interior de suas propriedades. Como notaram Clifford Shearing e Philip Stenning (1983) e Andrew von Hirsch e Clifford Shearing (2000), essa realidade é bem captada pelo provérbio inglês "a casa de um homem é o seu castelo", cuja origem remonta ao julgamento Entick versus Carrington, ocorrido na Inglaterra em 1765 e que representa um marco no desenvolvimento constitucional que impôs limites legais à ação do Poder Executivo.

Os direitos garantidos aos proprietários de controlar o interior de suas posses começaram a ser questionados por estudiosos e defensores das liberdades civis em razão da emergência e disseminação, a partir da segunda metade do século XX, de um novo tipo de configuração espacial que Shearing e Stenning $(1981,1983)$ chamaram de "propriedades privadas de massa" e outros vêm denominando de "espaços comunais" (Kempa, Stenning \& Wood, 2004), "enclaves fortificados" (Caldeira, 2003) e "espaços híbridos" (Kempa et alii, 1999). Essas configurações espaciais são 
formadas por áreas geográficas extensas que são usadas em massa para moradia, trabalho, lazer e consumo de bens e serviços. Por um lado, a polícia não tem o interesse e os recursos necessários para o policiamento dessas áreas; por outro, seus controladores preferem usar seguranças particulares para promover um tipo de ordem voltada para a satisfação de seus interesses.

A configuração das propriedades de massa desafia a congruência entre propriedade privada e espaço privado, empodera os seguranças particulares e abre a possibilidade para intrusões massivas e contínuas nas liberdades individuais com base em direitos concebidos inicialmente para proteger essas mesmas liberdades (Shearing \& Stenning, 1983; Stenning, 2000). Como essas propriedades oferecem bens e serviços importantes à vida contemporânea e são usadas coletivamente, elas estão mais próximas da ideia de espaço público do que de espaço privado. Todavia, os espaços das propriedades privadas de massa não são como os espaços públicos tradicionais que podem ser usados livremente por todos os indivíduos de um território nacional. Eles estão localizados dentro de propriedades cujo acesso depende de algum tipo de permissão e cujo uso deve estar de acordo com regras que vão além daquelas que regulam a vida nos espaços públicos convencionais. Os seus frequentadores estão sujeitos ao direito que os detentores de propriedades têm de controlar o acesso e o uso de suas posses. Esse controle geralmente é feito por seguranças particulares por meio de ferramentas variadas, dentre as quais se destacam as obstruções de entrada, as expulsões e as revistas em usuários.

A maior parte da bibliografia produzida na esfera anglo-saxônica vem afirmando que os poderes da segurança privada associados à propriedade não encontram limites legais semelhantes aos existentes para a polícia (Crawford, 2006; Hirsch \& Shearing, 2000; Sarre, 2003; Shearing \& Stenning, 1983; Shearing \& Wood, 2003; Stenning, 2000). Enquanto os cidadãos sujeitos ao policiamento nos espaços públicos dispõem de garantias constitucionais contra ações arbitrárias cometidas por policiais, os usuários de propriedades de massa estariam sujeitos ao poder arbitrário que os seguranças particulares recebem dos detentores de propriedades. A despeito das mudanças ocorridas no perfil das propriedades privadas, a bibliografia anglo-saxônica aponta que os sistemas normativos de países como Estados Unidos, Canadá e Reino Unido continuaram a reconhecer os direitos dos detentores de propriedade de regular o acesso e o uso de suas posses como se fossem espaços privados. Evidências disso têm sido fornecidas por algumas decisões judiciais envolvendo espaços quase públicos, especialmente no Reino Unido. As mais conhecidas são os casos CIN properties Ltd versus Rawlins and others (1995) e Appleby and others versus United Kingdom (2003). 
O julgamento CIN properties Ltd versus Rawlins and others (1995) envolveu tentativas do proprietário de um shopping center da cidade de Wellingborough, Inglaterra, de banir permanentemente um grupo de dez jovens frequentadores do local que foram acusados de perturbação. Os jovens foram inocentados pela Justiça, mas o shopping insistiu na tentativa de impedi-los permanentemente de ingressar em suas dependências sob o argumento de que aquele era um espaço privado. O caso foi julgado em 1995 por uma corte de apelação do Reino Unido, que acabou referendando o direito de os proprietários banirem os jovens indesejados. Já o caso Appleby and others versus United Kingdom (2003) diz respeito a um litígio envolvendo um grupo de moradores de Washington, nordeste da Inglaterra, que foram impedidos pelos seguranças de um shopping center de organizar um abaixo assinado no local. A expulsão dos moradores do shopping ocorreu sob a justificativa de que a empresa proprietária do estabelecimento não admitia a promoção de causas políticas e religiosas no local. O caso foi levado à Corte Europeia de Direitos Humanos pela organização de direitos civis Liberty (2008), que defendeu a tese de que em espaços quase públicos as pessoas podem exercer o direito de protestar pacificamente. Em 2003, a corte decidiu contra os moradores, alegando que o direito de protesto não tinha sido violado porque havia locais alternativos para realizar a manifestação.

Diante de casos como os relatados acima, Shearing e parceiros têm sustentado que as sociedades contemporâneas estão vivenciando uma mudança na natureza da própria governança (Bayley \& Shearing, 2001; Johnston \& Shearing, 2003; Shearing, 2003; Shearing \& Wood, 2003). Os autores partem da constatação de que boa parte da vida coletiva se desenvolve hoje no interior de propriedades de massa que estão sob o controle de atores não estatais, principalmente corporações. Essas corporações teriam não apenas o interesse e os recursos necessários para empregar forças de segurança privada em sua proteção, mas também condições para determinar a natureza da ordem a ser protegida, as regras necessárias para isso e o modo como elas devem ser impostas. Em outros termos, as corporações estariam atuando não apenas como provedoras de sua própria segurança, mas como verdadeiros governos privados capazes de definir e manter uma ordem de acordo com os seus interesses de maximização do lucro e que, não raramente, são conflitantes com direitos fundamentais como os de intimidade, de circular livremente e de se expressar. Isso estaria ocorrendo com o apoio do Estado, cujas estruturas legais reconhecem os poderes dos proprietários de prover segurança e governar domínios sociais expressivos.

A existência de governos privados justificaria, segundo Clifford Shearing e Jennifer Wood (2003), elaborações teórico-conceituais menos centradas no Estado. Os au- 
tores consideram que o Estado continua a existir como espaço relevante de governança e autoridade política, mas não necessariamente o mais importante. A realidade atual seria formada por núcleos de poder estatal e não estatal relativamente autônomos que eles chamam de nódulos de governança. O grau de autonomia, interconexão e importância de cada nódulo seria identificado empiricamente em tempos e espaços determinados. Consideram também que a noção de cidadania já não seria mais suficiente para captar a complexidade da realidade contemporânea porque designaria apenas o status político dos membros de um Estado territorial. Propõem então a noção de denizens para indicar os direitos e as responsabilidades vinculados à filiação dos indivíduos a diferentes domínios de governança.

As elaborações conceituais propostas pelos teóricos da governança nodal citados acima apoiam-se parcialmente no argumento de que os detentores de propriedades e os seguranças que trabalham para eles teriam poderes amplos para realizar exclusões, efetuar revistas e impor regras para acessar e usar os espaços que controlam. Todavia, as evidências de que isso vem ocorrendo nesses termos são limitadas e controversas. Os estudos existentes sobre o tema cobrem apenas alguns países com sistemas jurídicos de direito comum e estão baseados mais em evidências anedóticas do posicionamento do Estado em algumas decisões judiciais do que no estudo sistemático de um conjunto amplo de sentenças. Mesmo em países como o Reino Unido, Kevin Gray e Susan Francis Gray (1999), Mark Button (2007) e Alison Wakefield (2003) têm argumentado que parece estar ocorrendo uma mudança de um contexto normativo que admite poderes arbitrários no policiamento privado dos espaços quase públicos para outro na qual esses poderes somente podem ser empregados mediante justificativas razoáveis. Wakefielf (2003), por exemplo, considera que essa sinalização foi colocada no próprio julgamento Appleby and others versus United Kingdom (2003), no qual a Corte Europeia de Direitos Humanos reconheceu o direito dos seguranças do shopping center de proibir o protesto político dos moradores apenas porque a ação poderia ter sido realizada em outro local. Essas questões indicam que não estão claros na literatura britânica quais são os limites das ferramentas legais seletivas disponíveis aos seguranças particulares que atuam em propriedades de massa. Button (2007) sugere que os seguranças britânicos desfrutam de poderes arbitrários em propriedades de acesso restrito tais como plantas industriais e condomínios residenciais, mas apenas de poderes baseados em justificativas razoáveis em propriedades abertas ao público tais como shopping centers e complexos para entretenimento e lazer.

Se falta clareza sobre os limites dos poderes legais dos seguranças em um país com direitos civis reconhecidos, como é o caso do Reino Unido, sobram dúvidas sobre como essas questões se colocam em países com direitos civis pouco consolidados, 
como é o caso do Brasil. Dúvidas dessa natureza já haviam sido apontadas por Antônio Luiz Paixão (1991) no início dos anos 1990. Com o crescimento da segurança privada no Brasil nas últimas décadas (Lopes, 2013; Musumeci, 1998) e com as proporções que o setor apresenta atualmente (Rodrigues, Ribeiro \& Cano, 2019) essas dúvidas se amplificaram. Como notou Teresa Caldeira (2003), a democracia brasileira é marcada por uma disjunção entre os direitos civis, políticos e sociais que, em países como a Inglaterra, se formaram historicamente a partir de reforços mútuos: os direitos civis conquistados no século XVIII foram usados para a ampliação de direitos políticos no século XIX, que, por sua vez, serviram de base para a obtenção de direitos sociais no século XX (Marshall, 1967). No Brasil, essas dimensões da cidadania evoluíram de forma separada e os direitos sociais - e, secundariamente, políticos gozam de mais legitimidade que os direitos civis elementares, como a liberdade de ir e vir, de igualdade perante a lei, de proteção e acesso à justiça. Nesse contexto, é fundamental entender como as leis e os tribunais brasileiros têm tratado os poderes dos proprietários e seguranças nas propriedades privadas de massa. Esclarecer esse ponto é importante não apenas para entender a amplitude dos poderes que os seguranças particulares dispõem no policiamento dos espaços onde atuam, mas também para compreendermos melhor a natureza das transformações que estão ocorrendo na governança das sociedades contemporâneas. A segunda parte deste artigo busca contribuir para isso a partir de uma análise empírica dos poderes de obstrução de entrada, expulsão e revista disponíveis aos seguranças particulares.

\section{Metodologia}

A análise desenvolvida na sequência está baseada no estudo das normas que regulam as ações dos seguranças em propriedades de massa e na análise de 216 processos judiciais envolvendo o uso de poderes de obstrução de entrada, expulsão e revista cujo mérito foi julgado de forma colegiada pelo Tribunal de Justiça de São Paulo (TJSP) e pelo Tribunal de Justiça do Paraná (TJPR). Esses tribunais foram escoIhidos para o estudo em razão de suas jurisdições abrangerem as cidades de Londrina e São Paulo, que serão lócus de uma pesquisa futura sobre a confiança que os seguranças depositam nos poderes legais que possuem e sobre o modo como mobilizam tais poderes em suas rotinas de trabalho (Silva Lopes, 2018; Lopes, 2018).

A maioria dos processos analisados neste artigo foram extraídos de um banco de dados quantitativo e qualitativo sobre litígios decorrentes do uso de poderes universais e seletivos já utilizado em outro trabalho (Lopes, 2018). Esse banco é formado por 285 acórdãos julgados entre 2010 e 2012 pelo TJSP ( $n=221)$ e pelo TJPR ( $n=54)$ (Tabela 1). Aqui serão analisados os 153 acórdãos que tratam das consequências decorrentes da mobilização de poderes seletivos e os 44 que tratam das conse- 
TABELA 1

NÚMERO DE ACÓRDÃOS COLETADOS

TJSP E TJPR (2010-2011)

\begin{tabular}{|c|c|c|c|}
\hline & TJSP & TJPR & Total \\
\hline Ferramentas legais seletivas & 136 & 17 & 153 \\
\hline Ferramentas legais universais & 53 & 35 & 88 \\
\hline Ferramentas legais mistas* & 30 & 14 & 44 \\
\hline Total & 219 & 66 & 285 \\
\hline
\end{tabular}

quências da mobilização simultânea de poderes seletivos e universais mostrados na Tabela 1. A quase totalidade desses acórdãos (190 de 197) envolve alegações de danos morais causados por obstruções de entrada, expulsões ou revistas realizadas por seguranças em propriedades de massa.

Além dos processos mencionados anteriormente, também foram analisados acórdãos envolvendo tentativas ou ações empreendidas por shopping centers para impedir a realização de encontros de jovens em suas dependências - os chamados "rolezinhos" - com julgamento de mérito realizado de forma colegiada pelo TJSP e TJPR até dezembro de 2017. Por meio de uma busca de jurisprudência com a palavra "rolezinho" foram encontrados 19 processos judiciais: 3 pedidos de danos morais decorrentes da obstrução de menores de 18 anos desacompanhados dos pais (todos em São Paulo) e 16 pedidos de Interditos Proibitórios (15 em São Paulo e 1 no Paraná), ações judiciais cuja finalidade é prevenir agressões iminentes que

3. O Novo Código de Processo Civil define a ação de Interdito Proibitório nos seguintes termos: “Art. 567. O possuidor direto ou indireto que tenha justo receio de ser molestado na posse poderá requerer ao juiz que o segure da turbação ou esbulho iminente, mediante mandado proibitório em que se comine ao réu determinada pena pecuniária caso transgrida o preceito". ameaçam a posse de alguém e que os shoppings tentaram obter para impedir a entrada de jovens e a realização de "rolezinhos" em suas dependências ${ }^{3}$. Assim, ao todo são analisados neste artigo 206 acórdãos que acreditamos serem fundamentais para entender os fundamentos e os limites dos poderes seletivos usados pelos seguranças no policiamento de propriedades de uso coletivo.

Os acórdãos foram tratados e analisados de duas maneiras. Primeiramente, eles foram classificados em categorias-chave como tribunal julgador, decisão dos magistrados, tipo de poder mobilizado, local do litígio, dentre outras. Essas categorias foram usadas em uma análise quantitativa exploratória, cujo objetivo central foi descobrir o grau de legitimidade de cada um dos poderes analisados. Para entender quais são os fundamentos legais e os limites do direito de obstruir entradas, expulsar e revistar usuários de propriedades de massa, os acórdãos foram submetidos à análise de conteúdo (AC), implementada por meio do software Atlas.ti. Inicialmente, foram criados códigos genéricos para codificar trechos das decisões que continham: 
i. argumentos que reconheciam os poderes dos seguranças particulares; e

ii. argumentos que reconheciam limites a esses poderes.

Antes de iniciar a codificação, uma equipe composta por mim e mais cinco assistentes de pesquisa foi treinada em um projeto piloto $(n=25)$ realizado com o objetivo de maximizar a fidedignidade da AC. Esse piloto desenvolveu-se em três etapas, cada qual envolvendo a codificação simultânea de cerca de oito acórdãos por todos os membros da equipe. Essa duplicação de esforços serviu para construir um olhar comum para o corpus empírico e deu origem a um referencial de codificação (livro de códigos) contendo a descrição dos códigos, exemplos e instruções de como aplicá-los. Depois de obtidos níveis aceitáveis de fidedignidade no projeto piloto, todas as decisões judiciais foram codificadas pela equipe de pesquisa. O conteúdo resultante dessa primeira codificação foi então lido em profundidade por mim e recodificado para produzir a análise apresentada na próxima seção.

Resultados:

fundamentos e limites

das ferramentas legais seletivas da segurança privada

\section{Obstruções de entrada}

O poder de obstrução de entrada foi o mais contestado nos tribunais (95 de 216 casos - 44\%). A Tabela 2 mostra que o número de decisões favoráveis (51\%) e desfavoráveis (49\%) à realização de obstruções são parecidos, mas há diferenças importantes entre os tipos de propriedade. A grande maioria dos casos são obstruções realizadas em agências bancárias ( 68 de 95, 72\% dos casos). Em segundo lugar aparecem os litígios envolvendo tentativas de obstruções em shopping centers, com destaque para os pedidos de Interditos Proibitórios para barrar a entrada de jovens e a realização de "rolezinhos" (16 de 95, 17\% dos casos). Os demais casos são pouco expressivos numericamente.

A partir da discussão normativa realizada por Hirsch e Shearing (2000) sobre exclusões em espaços públicos e semipúblicos e das informações contidas nos processos judiciais coletados, uma análise mais aprofundada acerca das bases normativas e dos limites do poder de obstrução pode ser obtida se essa ação for divididas em três tipos:

i. obstruções baseadas em regras de acesso à propriedade; 
TABELA 2

POSICIONAMENTO EM RELAÇÃO ÀS OBSTRUÇÕES DE ENTRADA POR TIPO DE PROPRIEDADE. TJSP E TJPR (2010-2012)

\begin{tabular}{|c|c|c|c|}
\hline & Favorável & Desfavorável & Total \\
\hline Agência bancária (danos morais) & 40 & 28 & 68 \\
\hline Shopping center (interditos)* & 2 & 14 & 16 \\
\hline Shopping center (danos morais)** & 3 & 1 & 4 \\
\hline $\begin{array}{l}\text { Bar, restaurante, casa noturna (da- } \\
\text { nos morais) }\end{array}$ & 1 & 2 & 3 \\
\hline Outros (danos morais) & 1 & 2 & 3 \\
\hline Clube recreativo (danos morais) & 0 & 1 & 1 \\
\hline Total Geral & 47 (51\%) & $48(49 \%)$ & $95(100 \%)$ \\
\hline
\end{tabular}

ii. obstruções baseadas em desvios previamente cometidos; e

iii. obstruções preventivas baseadas em perfil social.

As obstruções baseadas em regras de acesso são as que ocorrem nas situações em que as pessoas descumprem normas de acesso às propriedades que são conhecidas e aceitas socialmente. É o caso das obstruções realizadas em propriedades privadas de massa que exigem autorização ou proíbem o acesso de pessoas com alimentos, bebidas alcoólicas, roupas impróprias, objetos metálicos etc. Obstruções desse tipo são as que mais desfrutam de legitimidade. O caso típico e mais frequente é o das agências bancárias. Como indicado na Tabela 2, a maioria das obstruções de entrada nesses estabelecimentos foi referendada pela Justiça (40 de 68, 59\% dos casos). A legitimidade que os seguranças de agências bancárias têm para obstruir entradas deriva de dois motivos inter-relacionados:

i. a particularidade situacional das agências, que são ao mesmo tempo frequentadas em massa e alvos atrativos para ações criminosas; e

ii. a regulação existente sobre o funcionamento de tais espaços, que são obrigados por lei a manter sistemas de segurança próprio que geralmente inclui porta giratória com trava detectora de metal instalada para impedir o ingresso de pessoas armadas - a Lei Federal 7.102/83 permite a instalação desse tipo de equipamento, mas não obriga as instituições financeiras a fazê-lo; já a Lei Estadual 11.571/96 obriga o uso do equipamento em todas as agências do estado do Paraná. 
Abaixo, trecho de decisão judicial típica que reconhece a legalidade de uma obstrução nesse tipo de espaço:

\begin{abstract}
A Lei 7.102/83, em seu artigo 2으, caput e incisos, disciplina o sistema de segurança das instituições financeiras e dá amparo ao uso de dispositivos como as portas com detectores de metais [...]. A adoção de tais mecanismos de segurança constituiu uma necessidade para as instituições bancárias, em virtude da atividade por elas desenvolvida, mas, mais que isso, o artigo 1으 da referida lei, veda o funcionamento das instituições que não possuírem o adequado sistema de segurança. [...] A finalidade da porta com detectores de metais é impedir atentados violentos contra as agências bancárias, assim, se esta é ativada pela presença de certa quantidade de metal (a suficiente para caracterizar uma arma), é dever dos prepostos do banco obstar o ingresso das pessoas que sejam barradas pelo dispositivo. Daí é que vem se consolidando o entendimento de que o uso de portas com detectores de metais em agências bancárias caracteriza, na verdade, o exercício regular de um direito (TJSP, P366: 03715745).
\end{abstract}

A obstrução de entrada em bancos é reconhecida como exercício regular de um direito. Assim, o poder dos seguranças de obstruir entradas encontra limite apenas nas situações em que há abuso de tal direito. Os tribunais consideraram que isso ocorreu em 28 dos 68 casos julgados (41\% dos litígios). A análise qualitativa desses casos sugere que tendem a ser consideradas abusivas as obstruções que ocorrem nas seguintes situações:

i. quando o equipamento falha, é travado discricionariamente pelo segurança, há abuso verbal, ou falta presteza para a resolução de obstruções ocasionadas por algum motivo conhecido e não relacionado à ameaça criminal; e

ii. quando ocorre a obstrução de pessoas com objetos metálicos comprovadamente implantados no corpo (prótese, marca passo, projétil, etc.).

A jurisprudência divide-se nos casos de obstruções de pessoas que vestem calçados com bico metálico (3 decisões favoráveis e 3 contrárias à obstrução). O trecho abaixo ilustra uma situação de obstrução em agência bancária que foi considerada abusiva:

O conjunto probatório deixa claro que a autora foi submetida desnecessariamente a situação constrangedora. Não se discute 
a necessidade da implementação de sistemas de segurança em agências bancárias - até porque se trata de exigência legal - mas é certo que, nos casos de falha evidente do mecanismo, os funcionários devem ser instruídos a solucionar o problema com presteza e discrição, de modo a evitar exposição indevida dos clientes. No caso concreto, o vigilante do réu deixou de tomar qualquer providência, não obstante tivesse testemunhado a autora se despojar de seus pertences. Poderia perfeitamente ter acionado o gerente para que este liberasse a entrada (fl. 19), mas optou por permanecer inerte, colocando a autora em situação vexatória perante os demais clientes (TJSP, P292: 0002941149).

As obstruções baseadas em desvios previamente cometidos são aquelas que visam impedir o acesso de pessoas que já tenham violado a lei ou as regras da propriedade em algum momento. Nos processos analisados encontramos uma única situação desse tipo. O caso envolvia um pedido de dano moral de uma mulher barrada pelo segurança de um bingo com base na justificativa de que ela tinha se comportado de maneira inadequada no passado. Não é possível fazer nenhuma inferência segura a partir deste caso único, mas é importante notar que a obstrução realizada pelo segurança foi julgada legal pelo tribunal. Eis um trecho desse julgamento:

Os prepostos da ré não agiram de forma desrespeitosa com a
autora, limitando-se a informar, de forma discreta, que ela não
poderia entrar no local, sob o argumento de que perturbava os
frequentadores do bingo, escolhendo cartelas para os clientes,
pedindo canetas emprestadas em pleno andamento dos sorteios
dos números, sentando-se às mesas dos clientes sem ser convi-
dada, pedindo dinheiro emprestado etc. Muito embora as tes-
temunhas da autora tenham negado tais alegações, as testemu-
nhas da ré confirmaram o fato de que certas atitudes da apelante
incomodavam os demais clientes, o que é provável (TJSP, P373:
20110000179894).

Por fim, as obstruções baseadas em perfil social são aquelas realizadas com base na premissa de que determinados indivíduos ou grupos sociais apresentam características que os tornam propensos a cometerem crimes ou causarem problemas aos detentores de propriedades. Enquanto as obstruções baseadas em regras encontram respaldo junto aos tribunais, as obstruções baseadas em perfil social são altamente polêmicas e legalmente contestáveis. Isso ocorre porque o poder de obstrução é mobilizado não com base em uma conduta concreta analisada à luz de uma regra e sim com base na expectativa futura de uma conduta danosa. A despeito dessa fragilidade, os dados indicam que, no contexto dos "rolezinhos", obstruções desse tipo foram referendadas pelo Judiciário em shopping centers. Assim, para entender a legitimidade e os limites das obstruções baseadas em perfil social 
é preciso analisar as estratégias adotadas pelos shopping centers para impedir a realização de "rolezinhos" e as respostas do Judiciário a elas.

Os shopping centers dos estados de São Paulo e Paraná usaram duas estratégias complementares para impedir encontros de jovens marcados pelas redes sociais em seus estabelecimentos. A primeira foi tentar obter da Justiça mandados para barrar a entrada de jovens e a realização dos eventos em suas dependências os chamados Interditos Proibitórios. O argumento utilizado nessas demandas judiciais foi que os "rolezinhos" visam "causar tumulto, amedrontar clientes, bem como efetuar, em algumas ocasiões, furtos e depredações" que afetam a "posse mansa e pacífica" das empresas administradoras de shopping centers (TJSP, P41420140000059987). Na maioria dos casos analisados, os mandatos foram solicitados contra jovens que convocavam os encontros nas redes sociais e eventuais participantes, mas em quatro ocasiões os shoppings também tentaram obter interditos para barrar irrestritamente a entrada de menores de 18 anos desacompanhados dos pais nos finais de semana. Essa estratégia não funcionou entre 2014 e 2016, quando a Justiça negou de forma unânime a expedição de Interditos Proibitórios. Formou-se nesse período uma jurisprudência baseada principalmente no argumento de que os temores demonstrados pelos shopping centers diante da iminência de "rolezinhos" não eram em relação à posse da propriedade e sim em relação à segurança de clientes e lojistas. Como são responsáveis pela segurança física e patrimonial das pessoas que frequentam seus espaços - argumentaram os magistrados -, os shopping centers deveriam adotar medidas protetivas próprias ou acionar a polícia para prevenir ou reprimir a ocorrência de delitos sem que para isso precisassem de mandato judicial proibindo a entrada de jovens em seus estabelecimentos. Algumas decisões foram além e sustentaram que não é lícito a espaços abertos ao público - como os shoppings centers - obstruir entradas e impedir o encontro de jovens para fins de lazer, sob pena de direitos como o de ir e vir, de reunião pacífica e de livre manifestação serem cerceados. Os trechos a seguir são representativos dessa jurisprudência.

De fato, é responsabilidade do estabelecimento comercial e seus administradores garantir a segurança de seus frequentadores; porém, isso não equivale dizer que possam transferir essa responsabilidade ao Poder Público, buscando a facilidade e conveniência da proibição pura e simples do ingresso de toda e qualquer pessoa que possa ser suspeita de participar do que se convencionou chamar de "rolezinho". É cômodo para os autores pretender transferir a responsabilidade à Justiça quando deveriam, por iniciativa própria, providenciar a segurança do shopping center, incrementando o número e a qualidade do serviço de proteção. Evidente o cerceamento à liberdade de quem, ainda que sem qualquer intuito 
de participar de "rolezinho", pretendesse frequentar o estabelecimento [...] (TJSP, P402: 20150000939838).

A ação de interdito proibitório é cabível quando preenchidos três requisitos, a saber: a) posse atual do autor; b) ameaça de turbação ou esbulho por parte do réu, e c) justo receio de ser concretizada a ameaça. No caso dos autos não se verifica o requisito da ameaça de turbação ou esbulho possessório. Nenhum fato foi relatado pelo autor que pudesse se traduzir em ameaça à posse ou em receio de concretização de ameaça. Ameaças às pessoas ou danos ao patrimônio se resolvem na área criminal. O autor teme a ocorrência de agressões e danos aos lojistas e aos frequentadores do shopping. Não está o autor preocupado com ameaça à sua posse. Neste caso, como muito bem observou o nobre Magistrado, o autor deve procurar a autoridade policial para prevenir e repreender eventuais delitos que possam vir a ser cometidos. [...] Depois, o local é destinado ao público em geral e por isso as medidas de proteção à posse são inadequadas (TJSP, P396: 20140000656573).

A unanimidade formada entre 2014 e 2016 nos tribunais analisados foi rompida em 2017 por meio da concessão de dois Interditos Proibitórios pelo Tribunal de Justiça de São Paulo. No Agravo de Instrumento 2004549-29.2017.8.26.0000, julgado pela 18a Câmara de Direito Privado em fevereiro de 2017, os magistrados entenderam que um "rolezinho" programado para ocorrer em um shopping de Guarulhos colocava em conflito o direito de propriedade e segurança dos proprietários e frequentadores do shopping, de um lado, e o direito de reunião e lazer dos jovens envolvidos com o "rolezinho", de outro. Ao final os magistrados decidiram que o direito de reunião não deveria prevalecer sobre o direito à locomoção e segurança dos frequentadores do shopping. A apelação 2017.0000620644, julgada pela 21ạ Câmara de Direito Privado em agosto de 2017, foi além e confirmou a concessão de um Interdito Proibitório pela Justiça de primeiro grau contra nove jovens organizadores de um "rolezinho" em um shopping de São Paulo sem sequer reconhecer a existência de qualquer tipo de conflito de direitos. Na ocasião, os magistrados decidiram que a imposição de um "escudo de proteção à posse do autor" era necessária e silenciaram sobre o direito de locomoção, reunião e protesto pacífico dos jovens alvos da ação. Essa nascente jurisprudência parece estar firmando o entendimento de que os shopping centers são espaços onde direitos fundamentais que vigoram nos espaços públicos são secundários diante dos direitos e responsabilidades das empresas proprietárias de shopping centers.

A segunda estratégia utilizada pelos proprietários de shopping centers para impedir a realização de "rolezinho" ocorreu paralelamente à primeira. Essa estratégia consistiu em barrar a entrada de menores de 18 anos desacompanhados dos pais 
nos dias em que havia "rolezinhos" agendados, independentemente da existência de mandado judicial para tanto. Esse tipo de ação foi questionado na Justiça de Segundo Grau em quatro alegações de danos morais (ver Tabela 2). O posicionamento firmado pela justiça nesse conjunto de decisões foi o de que obstruir a entrada nos shopping centers de menores de 18 anos constitui exercício regular de direito se o procedimento abranger todos os jovens. A única decisão desfavorável aos shopping centers reafirmou esse posicionamento ao condenar um shopping pelo fato de seus seguranças terem barrado a entrada de um jovem enquanto a de outros foi permitida ${ }^{4}$. O trecho a seguir é representativo desse posicionamento que respalda o poder dos seguranças para realizar obstruções baseadas em perfil no contexto dos "rolezinho".

Primeiramente importante mencionar que, à época, era comum a ocorrência dos denominados "rolezinho", reuniões de milhares de jovens em determinado shopping center, caracterizadas por violência contra os clientes, saques, furtos e depredação do patrimônio alheio. E, na data dos fatos, realmente havia informação de que no local ocorreria uma reunião da espécie (vide fls. 212/214), o que, inclusive, se concretizou (vide notícia jornalística de fls. 216/217 e 219). Diante dessa informação, o demandado, como medida de cautela, tomou certas providências para resguardar a integridade física e moral de seus clientes, dentre elas impedir o acesso, ao local, por menores desacompanhados de seus genitores e/ou responsáveis. [...] Percebe-se, assim, que aludida negativa foi totalmente justificada, estando de acordo com o contexto fático que se desenvolvia, qual seja, informações dando conta do agendamento de "rolezinho" no local, aglomeração de número exacerbado de adolescentes tentando ingressar no estabelecimento e responsabilidade do demandado pela segurança dos clientes do centro de compras. Tal conduta se traduz em exercício regular de direito, tendente à proteção da totalidade dos frequentadores do estabelecimento [...]. Exercer regularmente o direito de zelar pela segurança dos clientes, como na hipótese dos autos, não traduz descumprimento de qualquer dever legal (TJSP, P399: 20150000180590)

As evidências aqui apresentadas parecem indicar a existência de fundamentos e graus de legitimidade distintos para as obstruções de entrada. As obstruções realizadas com base em regras socialmente aceitas, como as que ocorrem diariamente em agências bancárias, desfrutam de alto grau de legitimidade. As obstruções baseadas em desvios previamente cometidos também parecem desfrutar de algum tipo de legitimidade, embora a escassez de situações desse tipo em nosso banco de dados não permita nenhuma conclusão taxativa. Por fim, as obstruções baseadas em perfil social parecem ser as mais frágeis de se sustentarem, mas o posiciona-

4. Trata-se da Apelação 990.10.1610396 , julgada pela 5a Câmara do Tribunal de Justiça de São Paulo em outubro de 2010, momento em que os encontros de jovens marcados por meio de redes sociais ainda eram desconhecidos da grande mídia. Nesse processo os magistrados condenaram o shopping por danos morais pelo fato de o segurança ter barrado um menor desacompanhado dos pais enquanto permitiu a entrada de outros. Ou seja, a condenação decorre não da obstrução em si e sim do fato de ela ter sido direcionada a alguns e não a outros. 
mento do judiciário paulista no contexto dos "rolezinho" indica que tais medidas também podem encontrar respaldo dentro do nosso contexto jurídico.

\section{Expulsões}

A obstrução de entrada é um dos poderes disponíveis aos seguranças para impedir que determinadas pessoas usufruam de espaços localizados no interior de propriedades. Esse impedimento também pode ocorrer por meio do poder de expulsão. Obstrução de entrada e expulsão apontam para uma mesma questão: a capacidade que os detentores de propriedade têm - e delegam aos seguranças - de promover exclusões de pessoas de suas posses. Os dados da Tabela 3 mostram que a maioria dos litígios envolvendo a expulsão de pessoas por seguranças foi julgada legal pelos tribunais analisados (15 de 27, 56\% dos casos), sinalizando assim para a legitimidade dessas ações. Em 12 dos 27 casos julgados (44\%), os processos envolvendo expulsões resultaram em condenações por danos morais.

A discussão realizada na seção anterior mostrou que o principal fator que confere legitimidade ao poder de obstrução de entrada é a existência de regras socialmente aceitas de acesso à propriedade. A análise das decisões judiciais envolvendo expulsões de propriedades apontam que a legitimidade desse poder deriva dessa mesma situação. Tanto as obstruções quanto as expulsões podem ser realizadas diante das situações em que há o descumprimento de regras de acesso e uso da propriedade. Enquanto as obstruções funcionam como negativa de acesso à propriedade, as expulsões funcionam como revogação da permissão de acesso anteriormente concedida. Essa revogação e a consequente expulsão tendem a ser consideradas legítimas sempre que alguém apresenta comportamento inapropriado no interior de uma propriedade. Comportamento inapropriado aqui não é sinô-

TABELA 3

POSICIONAMENTO EM RELAÇÃO ÀS EXPULSÕES

POR TIPO DE PROPRIEDADE. TJSP E TJPR (2010-2012)

\begin{tabular}{|c|c|c|c|}
\hline & Favorável & Desfavorável & Total \\
\hline Bar, restaurante, casa noturna & 7 & 5 & 12 \\
\hline Outros & 3 & 2 & 5 \\
\hline Shopping center & 1 & 2 & 3 \\
\hline Clube recreativo & 1 & 2 & 3 \\
\hline Terminal ou veículo de transporte coletivo & 2 & 0 & 2 \\
\hline Estabelecimento comercial & 1 & 1 & 2 \\
\hline Total Geral & $15(56 \%)$ & $12(44 \%)$ & $27(100 \%)$ \\
\hline
\end{tabular}


nimo de comportamento desviante em relação à lei. Proprietários têm o direito de definir regras de conduta no interior de sua propriedade que transcendem aquelas que vigoram no espaço público, tais como impedir que pessoas andem descalças ou sem camisa no interior de shoppings ou casas noturnas. Em alguns casos essas regras estão definidas em lei e compete aos possuidores de propriedades garantir o seu cumprimento, sob pena de serem sancionados pelo Estado, como ocorre com a Lei Federal 12.546/11, que proíbe fumar em espaços de uso coletivo fechados ou parcialmente fechados. Em outros casos essas regras estão explicitadas em regulamentos internos. Em outros, estão apenas subentendidas, como ocorre com a regra "se brigar perde o direito à diversão" em vigor nos espaços destinados ao entretenimento e ao lazer.

Do ponto de vista do usuário, a obstrução e a expulsão representam uma sanção ao descumprimento das regras que regulam o uso da propriedade. A expulsão pode ocorrer de forma negociada por meio de um convite para que a pessoa se retire do local, ou de forma impositiva por meio do uso de força física. A citação a seguir traz um exemplo da licitude perante os tribunais analisados do poder impositivo de expulsão.

[...] como bem salientou o nobre magistrado, "[...] o réu sobretudo com depoimento da segunda testemunha logrou comprovar que o autor e mais alguns colegas não se comportavam de maneira adequada. Chama a atenção deste Juízo o fato de que o segurança não deu um tapa ou um soco ou um chute no autor, apenas o imobilizou, retirando-o do estabelecimento. Por mais lamentáveis que sejam os acontecimentos não é possivel imputar a responsabilidade ao shopping porque ficou demonstrado que este se comportou de maneira lícita" (TJSP, P203: 20110000110330 - destaque no original).

Embora as expulsões possam ser realizadas pelos seguranças de maneira legítima, as sentenças analisadas indicam que elas tendem a ser consideradas ilegais quando são realizadas mediante uso inadequado de força física. Estudo realizado por Lopes (2018) já tinha demonstrado que os tribunais de São Paulo e Paraná têm julgado casos de uso de força física envolvendo segurança particulares com base nos mais exigentes princípios nacionais e internacionais que regulam o uso da força por agentes de segurança: necessidade, conveniência, proporcionalidade, moderação e legalidade. O trecho abaixo, retirado de um processo envolvendo a expulsão de um adolescente de um parque de diversão da cidade de São Paulo, exemplifica as outras duas circunstâncias em que expulsões são consideradas ilegais: quando é realizada com base em uma falsa acusação de violação do regulamento em vigor na propriedade; e quando feita de forma inconsequente, colocando em risco a pessoa expulsa. 
[...] restou isolada a tese da apelante de que o autor adentrou e permaneceu em seu estabelecimento de forma gratuita e indevida. Pelo contrário, a prova documental carreada à inicial demonstra a verossimilhança das alegações do autor que era aluno da Escola Estadual Professor Licínio Carpinelli (fls. 18) e que compôs a relação de passageiros para a excursão realizada com destino ao parque Playcenter (19). [...] Assim, absolutamente nada afasta sua responsabilidade civil por ter expulsado menor de seu estabelecimento, localizado nesta Capital, lançando-o à via pública, exigindo-lhe o retorno à escola, que se localiza na cidade de Guarulhos, por seus próprios meios (TJSP, P315: 20120000246847).

Em suma, a análise qualitativa das decisões judiciais indica que as expulsões tendem a ser consideradas ilegais quando

i. ocorrem mediante o uso inadequado de força física;

ii. o motivo para a expulsão não se mostra presente ou é insuficiente; e

iii. resulta em consequências potencialmente danosas para a pessoa excluída do espaço.

Por outro lado, as expulsões tendem a ser aceitas quando direcionadas a pessoas cujo comportamento tenha violado as regras que regulam o uso da propriedade. Isso significa que o poder de expulsão tem um alcance mais limitado do que o poder de obstrução. Enquanto as expulsões podem ser realizadas apenas contra pessoas cujo comportamento tenha violado normas internas às propriedades, as obstruções também podem ser realizadas contra pessoas cujo comportamento pretérito tenha violado tais regras ou que sejam percebidas como parte de um grupo social considerado perigoso à ordem privada das propriedades de massa.

\section{Revistas em usuários}

5. Para uma análise do poder de revista em trabalhadores, ver Silva Lopes (2018).
Se os poderes de obstrução de entrada e expulsão indicam a capacidade que os seguranças têm para excluir indivíduos das propriedades onde atuam, o poder de revista aponta para a capacidade que têm de realizar intrusões na privacidade dos indivíduos que frequentam essas propriedades. As revistas em usuários de propriedades de massa podem ser divididas em dois tipos:
i. revistas como condição de acesso às propriedades; e
ii. revistas sob fundada suspeita da posse de produto ilícito no interior da propriedade 5 . 
As revistas como condição de acesso às propriedades estão fundamentadas nos mesmos direitos descritos anteriormente para o caso das obstruções de entrada e expulsões. Os detentores de propriedade podem exigir que as pessoas se submetam a revistas como condição de acesso aos espaços sob o seu controle. Em algumas situações, as revistas como condição de acesso não são apenas um direito, mas um dever dos responsáveis pela propriedade. O artigo 34 da Lei 10.826/03 (Estatuto do Desarmamento), por exemplo, obriga os organizadores de eventos em locais fechados com aglomeração superior a mil pessoas a adotarem medidas necessárias para impedir o ingresso de pessoas armadas. O artigo 13-A da Lei 10.671/03 (Estatuto do Torcedor) também confere poder de revista aos seguranças que atuam em recintos esportivos quando impõe uma série de exigências de acesso e permanência de torcedores nesses espaços. O Regulamento Brasileiro da Aviação Civil também obriga os administradores de aeroportos a realizarem inspeções em bagagens e passageiros. A própria Lei 7.102/83, que regulamenta os sistemas de segurança de instituições financeiras, também confere aos seguranças o poder de revistar pessoas barradas na porta giratória com o objetivo de averiguar a presença de objetos metálicos. Com base nessas leis, seguranças que atuam em eventos, arenas esportivas ou agências bancárias estão legalmente autorizados a realizar revistas como condição de acesso às propriedades ${ }^{6}$. Os que atuam em outras áreas não regulamentadas por lei também podem conduzir esse tipo de revista em nome da segurança do espaço e de seus frequentadores. Diferentemente do que ocorre com as revistas realizadas por policiais, os indivíduos não são obrigados a se submeterem às revistas realizadas por seguranças na entrada de propriedades de massa. Todavia, a não submissão implica em ter o acesso ao espaço negado.

Há pouca controvérsia em relação à legitimidade das revistas como condição de acesso às propriedades. O número relativamente reduzido de litígios que chegaram ao TJSP e ao TJPR entre 2010 e 2012 pode ser lido como um indicativo disso. Dos 78 processos sobre revistas realizadas por seguranças que foram localizados, apenas sete dizem respeito a revistas como condição de acesso à propriedade. Esses sete processos são referentes a revistas em agências bancárias e as duas decisões desfavoráveis ao procedimento têm a ver mais com excessos no seu uso do que com a prática da revista em si (ver tabela 4).

Dois pareceres emitidos pela Polícia Federal, órgão regulador do setor de segurança privada no Brasil, também apontam para a legitimidade e os limites das revistas realizadas por seguranças: Parecer 4675/07-DELP/CGCSP; e Parecer 694/13-DELP/ CGCSP. O trecho abaixo, extraído do parecer mais recente, resume o entendimento da Polícia Federal sobre o tema:

6. Esses três exemplos não são exaustivos e poderíamos acrescentar outros como as revistas realizadas em aeroportos como condição de acesso à área de embarque. 
TABELA 4

POSICIONAMENTO EM RELAÇÃO ÀS REVISTAS EM USUÁRIOS

POR TIPO DE PROPRIEDADE. TJSP E TJPR (2010-2012)

\begin{tabular}{|c|c|c|c|c|c|c|}
\hline & \multicolumn{2}{|c|}{ Total } & \multicolumn{2}{|c|}{ TJSP } & \multicolumn{2}{|c|}{ TJPR } \\
\hline & Favorável & Desfavorável & Favorável & Desfavorável & Favorável & Desfavorável \\
\hline Estabelecimento comercial & 20 & 42 & 20 & 24 & 0 & 18 \\
\hline Agência bancária & 5 & 2 & 5 & 2 & 0 & 0 \\
\hline Shopping center & 0 & 4 & 0 & 4 & 0 & 0 \\
\hline Bar, restaurante, casa noturna & 0 & 2 & 0 & 2 & 0 & 0 \\
\hline Indústria & 0 & 1 & 0 & 1 & 0 & 0 \\
\hline Outros & 1 & 0 & 1 & 0 & 0 & 0 \\
\hline Prédio do governo & 1 & 0 & 1 & 0 & 0 & 0 \\
\hline Total Geral & $27(35 \%)$ & $51(65 \%)$ & $27(45 \%)$ & $33(55 \%)$ & $0(0 \%)$ & $18(100 \%)$ \\
\hline
\end{tabular}

[...] esse procedimento de iniciativa particular não encontra previsão expressa em nenhuma regulamentação especifica sobre a matéria, mas decorre da própria autorização estatal para o desempenho da atividade segurança privada, na prevalência do interesse da coletividade e da segurança dos estabelecimentos e pessoas frequentadoras do local protegido, justificando a sua existência plenamente. [...] essa Divisão de Legislação e Pareceres da Coordenação-Geral de Controle de Segurança Privada-DELP/CGCSP/DIREX manifesta-se, novamente, pela procedência do exercício da atividade de revista privada realizado por vigilantes. [...] Insta ressaltar que o tratamento dispensado a todos deve ser igualitário e o procedimento apenas superficial, com a anuência do revistado, o que pressupõe a ausência de coerção e o seu prévio conhecimento quanto à imposição do ato e sua forma. Entende-se por revista superficial aquela realizada mediante observação visual e toque das mãos do "agente buscador" por cima das roupas do revistado [...] Ressalte-se, em resumo, que a revista privada não tem o caráter coercitivo da busca pessoal, realizada por agentes policiais e prevista no art. 244 do Código de Processo Penal, mas depende de consentimento do sujeito passivo da revista, ocorrendo que, na sua recusa, os procedimentos possíveis para o corpo de segurança privada são: nos casos de condição de ingresso a determinado recinto, não permitir esta entrada e, nas ocorrências já situadas no interior do estabelecimento, havendo fundada suspeita (furto, roubo, agressão etc.), deter momentaneamente o indivíduo até a chegada da Polícia que deve ser imediatamente acionada, para que esta proceda à busca pessoal no indivíduo e adote as demais medidas pertinentes (Parecer 694/13-DELP/CGCSP; destaque no original).

A passagem acima revela de maneira explícita os limites das revistas realizadas por seguranças: necessidade de o procedimento estar explicitado, ser igualitário, con- 
sentido e superficial. Aponta também para as diferenças entre o poder de revista de policiais e seguranças particulares. Enquanto os primeiros estão autorizados pelo artigo 244 do Código de Processo Penal a realizar "busca pessoal" nos casos de prisão, fundada suspeita da posse de objetos ilícitos ou autorização judicial, os segundos podem realizar "revista privada" apenas como condição de acesso às propriedades. Nas situações de fundada suspeita da posse de produtos ilícitos o parecer determina que os seguranças devem deter momentaneamente a pessoa e acionar a polícia para que ela proceda à busca pessoal. Essa determinação indica que os seguranças não estão autorizados a realizar revistas sob fundada suspeita tal como estão os policiais. Entretanto, a análise dos litígios sobre revistas julgados pelo TJSP e pelo TJPR entre 2010 e 2012 aponta para uma realidade mais nuançada do que a indicada pelo parecer da Polícia Federal.

Com exceção dos sete litígios registrados em agências bancárias apontados anteriormente, todos os demais encontrados nos tribunais analisados são referentes a revistas feitas por seguranças particulares em pessoas suspeitas de estarem na posse de produtos furtados ou ilícitos (ver tabela 4). A grande maioria dos casos são revistas em consumidores realizadas na saída de estabelecimentos comerciais, principalmente grandes redes varejistas (62 de 78, 79\% dos casos). As decisões desfavoráveis ao procedimento prevalecem, mas há diferenças importantes entre os tribunais. Enquanto o TJPR tem um posicionamento coeso pró-condenação de revistas em clientes de estabelecimentos comerciais (18 decisões desfavoráveis contra nenhuma favorável) que está alinhado com o entendimento da Polícia Federal sobre a ilegalidade das revistas privadas sob fundada suspeita, o TJSP tem um posicionamento dividido (20 decisões favoráveis contra 24 desfavoráveis) acerca desse procedimento. Esse tribunal tende a aceitar as revistas realizadas após disparo de alarme antifurto instalado na saída dos estabelecimentos comerciais.

\footnotetext{
Constatou-se que, por negligência do atendente do caixa, não foi retirado o dispositivo de segurança dos produtos, provocando o acionamento do alarme e a consequente abordagem pelos seguranças do estabelecimento. [...] após o disparo do alarme de segurança, solicitaram a revista nas mercadorias da autora, atitude esta que, se levada de maneira ponderada e discreta, como foi, configura exercício regular de direito, não ensejando direito à indenização (TJSP, P141: 0002928722)
}

Como mostra o trecho acima, as revistas em pertences realizadas após o disparo de alarme podem ser consideradas exercício regular do direito de vigilância e defesa do patrimônio dos estabelecimentos comerciais se forem realizadas de maneira ponderada e discreta. Mesmo revistas corporais realizadas sob fundada suspeita 
provocada por motivos outros que não o disparo do alarme podem ser consideradas legais se houver o entendimento de que foram realizadas sem exposição indevida da pessoa revistada. O que constitui exposição indevida varia consideravelmente. Os casos citados a seguir dão uma amostra dessas variações de entendimento presentes no âmbito do TJSP:

\begin{abstract}
O autor realmente foi abordado pelos seguranças da ré e revistado publicamente [foi pedido para que "mostrasse publicamente $o$ que carregava sob suas vestes"], causando-lhe constrangimentos perante os demais frequentadores do local. Os estabelecimentos comerciais têm o direito de contratar serviço de segurança particular a fim de evitar a ocorrência de infrações em suas dependências. Entretanto, a abordagem deve ser discreta, para evitar a configuração de situação vexatória ao consumidor sob suspeita, devendo este ser encaminhado à local reservado e afastado da movimentação a fim de ser inquirido sobre os fatos imputados (TJSP, P142: 0002978929).
\end{abstract}

Ao que consta, a Autora foi acusada de furto e reconduzida ao interior do estabelecimento comercial da Ré, onde teve seus pertences revistados, não obstante ter dito à funcionária da loja que pagara pelas mercadorias que portava. [...] a mera abordagem sob acusação de furto, já causa o dano psicofísico descrito; constrange o íntimo do ser humano normal. [...] Não se pode negar que a abordagem, a acusação de furto e a revista dos pertences levados por pessoa insuspeita, causa constrangimento e humilhação a justificar a reparação [...] (TJSP, P109: 0003527485).

Enquanto na primeira decisão a situação vexatória e ilegal ocorre pelo fato de uma pessoa ter sido revistada em público quando deveria ter sido encaminhada para local reservado para averiguação da suspeita, a segunda decisão aponta para uma situação em que o encaminhamento da pessoa suspeita para revista em pertences em sala reservada por si só é considerado uma ação causadora de constrangimento. Nesse contexto, as revistas feitas por seguranças para coibir furtos em propriedades de massa podem facilmente ser consideradas ilegais se realizadas sem o consentimento das pessoas e provocarem algum tipo de resistência capaz de chamar a atenção do público. Assim, embora as revistas feitas por seguranças para coibir furtos em propriedades de massa sejam consideradas legítimas pelo TJSP, mesmo sem a presença de consentimento por parte do abordado, as condições concretas de sua realização podem facilmente ensejar o entendimento de que foram realizadas de maneira abusiva. Isso é bem mais difícil de ocorrer no caso das revistas como condição de acesso às propriedades, que desfrutam de grande legitimidade. 


\section{Análise e discussão}

Espaço público, ordem pública e polícia formam uma tríade central para a compreensão do modo como as sociedades liberais estão organizadas. Os espaços públicos são áreas de livre circulação e expressão cuja ordem é definida por normas estatais que devem ser impostas pela polícia de acordo com a lei. Assim, o direito à circulação e expressão que os cidadãos detêm nos espaços públicos somente pode ser limitado em situações excepcionais previstas em lei ou mediante a aplicação de sanções privativas de liberdade que devem obedecer às regras do devido processo legal. Essas regras também devem ser observadas em ações policiais intrusivas tais como as abordagens e revistas, que somente podem ser realizadas quando há um mandado judicial autorizando o procedimento ou uma suspeita razoável acerca da presença de algum bem ilícito a ser apreendido. Em suma, o modelo normativo que dá vida às noções de espaço público e ordem pública nas sociedades liberais visa maximizar liberdades individuais como a de se movimentar e se expressar livremente sem intromissões indevidas do Estado e de terceiros, razão pela qual prevê uma série de mecanismos formais para limitar o poder dos agentes estatais para vasculhar a intimidade dos indivíduos e para excluir pessoas dos espaços públicos. A dimensão civil da cidadania apoia-se nessas ideias de maximização de liberdades individuais e contenção da capacidade do Estado de interferir nelas.

A análise realizada ao longo deste artigo mostra que a disseminação das propriedades privadas de massa tem impactos consideráveis no modelo normativo descrito acima. As evidências apresentadas sugerem que alguns usuários de propriedades de massa estão legalmente sujeitos a poderes de exclusão mais amplos do que estão os cidadãos que usam os espaços públicos tradicionais controlados pela polícia. Seguranças detêm legitimidade para excluir pessoas de determinados espaços por meio de obstruções baseadas em comportamento passado; obstruções e expulsões baseadas em regras e comportamento presente; e obstruções baseadas em perfil social. Também detêm legitimidade para realizar intrusões nas liberdades individuais por meio de revistas baseadas em regras de acesso às propriedades e, em menor medida, em revistas realizadas sob a fundada suspeita da posse de algum bem ilícito. Em linhas gerais, essas descobertas são convergentes com aquelas presentes em estudos realizados em países de língua inglesa (Crawford, 2006; Hirsch \& Shearing, 2000; Sarre, 2003; Shearing \& Stenning, 1983; Shearing \& Wood, 2003; Stenning, 2000).

O reconhecimento legal desses poderes de exclusão e intrusão indica que o Estado brasileiro tem contribuído ativamente para a conformação de nódulos de governança (Shearing \& Wood, 2003), cujo funcionamento desafia a já frágil dimensão 
7. A regra é uma das 14 que constam no código de conduta do Aurora Shopping Center, inaugurado em 2016 em um dos bairros mais nobres da cidade de Londrina. Depois de elencar as 14 normas de conduta que definem a ordem interna ao shopping center, há no código o aviso de que "A violação dessas normas de conduta poderá acarretar na restrição de acesso ou permanência de qualquer pessoa em nossas dependências". civil da cidadania disjuntiva brasileira (Caldeira, 2003). As exclusões impostas pelas obstruções baseadas em comportamento passado desafiam as liberdades individuais que estão na base da cidadania moderna por ao menos duas razões, como apontam Hirsch e Shearing (2000). A primeira é que os procedimentos usados pelos detentores de propriedade para definir um comportamento como inapropriado podem ser arbitrários e desconsiderar qualquer possibilidade de defesa, abrindo a possibilidade para a aplicação de sanções injustas. A segunda é que esse tipo de obstrução pode ser absolutamente alheia à ideia de pena proporcional que vigora nos sistemas públicos de justiça em sociedades liberais. Os poderes dos seguranças que se fundamentam em comportamentos presentes e regras internas às propriedade também colocam desafios às liberdades individuais. Uma parte das regras que legitimam as obstruções de entrada, as expulsões e as revistas realizadas por seguranças são decorrentes de normas públicas que foram discutidas e aprovadas por autoridades políticas legítimas - caso das regras que regulam o funcionamento de bancos, aeroportos, estádios de futebol, eventos de grande porte e o consumo de cigarros em ambientes coletivos fechados. Mas outra parte são regras privadas cuja criação não está sujeita a nenhum mecanismo de accountability público e que podem definir critérios arbitrários e discriminatórios para acesso e permanência nas propriedades que contrariam o ideal de cidadania e espaço público. Depois da onda dos "rolezinhos", por exemplo, alguns shopping centers inseriram nas regras que regulam condutas em seus estabelecimentos que "grupos com mais de cinco pessoas podem ser solicitados dispersarem-se em grupos menores", concedendo assim alto grau de discricionariedade para que seguranças regulem as condutas de indivíduos considerados indesejáveis?

Foi também nos shopping centers que encontramos decisões judiciais referendando exclusões baseadas em perfil social que são ameaçadoras de uma séria de direitos assegurados nos regimes políticos liberais, dentre os quais o da presunção de inocência e individualidade da culpa. As obstruções generalizadas de jovens realizadas pelos shopping centers no contexto dos "rolezinhos" foram baseadas na incriminação preventiva de um grupo social visto como perigoso: os jovens da periferia que ousaram circular pelos shoppings center para mostrar seus estilos, conhecer pessoas e se divertir. Ao referendar essas obstruções, seja diretamente por meio dos Interditos Proibitórios concedidos em 2017 ou indiretamente por meio das negativas de danos morais nos processos movidos por jovens contra os shoppings, o TJSP reconheceu legitimidade a um procedimento estranho ao modelo normativo da ordem sob a lei. Enquanto este modelo está baseado na ideia de que restrições ao direito de circular e se expressar nos espaços públicos somente podem ser aplicadas contra indivíduos que adotam condutas tipificadas como crime, as restrições impostas pelos seguranças dos shopping centers no contexto dos 
"rolezinhos" basearam-se na ideia de culpa coletiva e preventiva. Assim, os jovens foram submetidos ao que Michel Misse (2014) tem chamado de "sujeição criminal", que é um processo social marcado pelo deslocamento da incriminação de condutas tipificadas no Código Penal para a incriminação de indivíduos e grupos sociais específicos. Foi um deslocamento desse tipo que fez com que a presunção de inocência desse lugar à desconfiança generalizada de que adolescentes representavam um risco à segurança dos frequentadores de shoppings, legitimando assim a adoção de medidas preventivas como as obstruções de entrada.

Essa realidade sugere que os direitos individuais que compõem a cidadania moderna não estão normativamente assegurados no interior das propriedades privadas de massa. A capacidade de governança que o Estado confere aos possuidores de propriedades e aos seguranças que atuam nelas contribui para a constituição de nódulos de governança que funcionam com base em normas próprias. Nos termos propostos pela teoria da governança nodal, essas normas transformam as pessoas que circulam pelas propriedades de massa em denizens cujos direitos se subordinam à lógica que perpassa a ordem local dominante. Em shopping centers, por exemplo, os denizens têm o direito de usufruir do espaço para consumo e passeios contemplativos, mas não para usos que subvertam a lógica comercial inerente a esse nódulo de governança.

\section{Considerações finais}

Este trabalho buscou oferecer uma contribuição para os estudos sobre controle social formal por meio de uma análise das ferramentas legais mais mobilizadas no policiamento dos usuários das propriedades privadas de massa. A análise aponta para o fato de que o Estado brasileiro confere poderes consideráveis para que os detentores de propriedades e seus seguranças realizem obstruções, expulsões e revistas em indivíduos e grupos sociais específicos. Essas "ferramentas legais seletivas" (Button, 2007) viabilizam um tipo de governança não estatal cujas práticas de controle social não raramente se chocam com o direito à intimidade, livre circulação e manifestação previstos aos cidadãos nos espaços públicos. Assim, a realidade analisada parece corroborar a ideia defendida pelos teóricos da governança nodal de que os indivíduos que circulam por esses "nódulos de governança" são denizens cujos direitos e deveres estão condicionados não ao seu status de cidadania, mas à natureza da ordem vigente nas propriedades de massa (ver Shearing \& Wood, 2003).

Diante do exposto, parece claro que a proliferação das propriedades privadas de massa traz implicações consideráveis para a natureza do controle social formal e para as liberdades individuais no Brasil. Embora a tendência dominante no TJSP e 
no TJPR no período estudado tenha sido a de reconhecer limites à capacidade que os seguranças têm de regular o acesso e o uso das propriedades que controlam, no TJSP encontramos posicionamentos que referendavam poderes amplos para que seguranças obstruíssem entradas em locais como shopping centers, que são propriedades privadas abertas ao público. Estudos adicionais precisam ser realizados para descobrir se esse posicionamento permissivo do judiciário em relação aos poderes dos seguranças particulares tem realmente ganhado espaço no Brasil e em outros contextos. Ao considerar que boa parte da vida coletiva se deslocou dos espaços públicos convencionais para espaços localizados em propriedades privadas de massa, o entendimento dessas questões importa não apena por razões acadêmicas, mas também políticas. Se a contenção do poder é um imperativo para a realização de liberdades individuais, deveríamos começar a pensar em como estender as garantias constitucionais existentes contra ações arbitrárias realizadas pela polícia nos espaços públicos para as ações realizadas por seguranças particulares em espaços semipúblicos como o dos shopping centers. A solução talvez passe por conceber as áreas comuns de shopping centers não como espaços sujeitos a regras baixadas por particulares e sim como espaços públicos sujeitos a regras similares às que vigoram nos espaços públicos tradicionais.

\section{Referências}

BAYLEY, D.; SHEARING, C. The new structure of policing: description, conceptualization, and research agenda series. Research Report, 2001.

BUTTON, M. Security officers and policing: powers, culture and control in the governance of private space. Aldershot (UK); Burlington (NJ): Ashgate Publishing, Ltd., 2007.

CALDEIRA, T. P. Cidade de muros: crime, segregação e cidadania em São Paulo. 2. ed. São Paulo: Editora 34; Edusp, 2003.

CRAWFORD, A. Policing and security as "club goods": the new enclosures? In: WOOD, J.; DUPONT, B. (Eds.). Democracy, society and the governance of security, p. 111-138. New York: Cambridge University Press, 2006.

GRAY, K.; GRAY, S. F. Civil rights, civil wrongs, and quasi-public space. European Human Rights Law Review, p. 1-59, 1999.

HIRSCH, A. VON; SHEARING, C. D. Exclusion from public space. In: HIRSCH, A. V.; GARLAND, D.; WAKEFIELD, A. (Eds.). Ethical and social perspectives on situational crime prevention, p. 241. Oxford (UK): Hart Publishing, 2000. 
JOHNSTON, L.; SHEARING, C. D. Governing security: explorations in policing and justice. London: Routledge, 2003.

KEMPA, M.; STENNING, P.; WOOD, J. Policing communal spaces. A reconfiguration of the "mass private property" hypothesis. British Journal of Criminology, v. 44, n. 4, p. 562-581, 7 Jan. 2004.

KEMPA, M. et alii. Reflections of the evolving concept of "private policing". European Journal on Criminal Policy and Research, v. 7, n. 2, p. 197-223, 1999.

LIBERTY. Liberty's supplementary evidence to the Joint Committee on Human Rights: "policing and protest" - private property. Londres: National Council for Civil Liberties, 2008. Disponível em: <https://www.libertyhumanrights.org.uk/sites/default/ files/supplementary-evidence-to-jchr-protest-and-private-land-.pdf>.

LOPES, C. da S. As ferramentas legais universais da segurança privada: Um estudo sobre os direitos de questionar, usar força física e prender dos seguranças particulares brasileiros. Dilemas - Revista de Estudos de Conflito e Controle Social, v. 11, n. 1, p. 97-126, Maio 2018.

O setor de segurança privada da região metropolitana de São Paulo: crescimento, dimensões. Caderno CRH, v. 26, n. 69, p. 599-617, Dez. 2013.

MARSHALL, T. H. Cidadania, classes sociais e status. Rio de Janeiro: Zahar, 1967.

MISSE, M. Sujeição criminal. In: LIMA, R. S. D.; RATTON, J. L.; AZEVEDO, R. G. de A. (Eds.). Crime, polícia e justiça no Brasil. São Paulo: Contexto, 2014.

MUNIZ, J. O.; PAES-MACHADO, E. Polícia para quem precisa de polícia: contribuições aos estudos sobre policiamento. Caderno CRH, v. 23, n. 60, p. 437-447, 2010.

MUSUMECI, L. Serviços privados de vigilância e guarda no Brasil: um estudo a partir de informações da Pnad - 1985-1995. Diagnóstico do setor serviços no Brasil. Rio de Janeiro: MICT/Ipea/Anpec, 1998.

PAIXÃO, A. L. Segurança privada, direitos humanos e democracia: notas preliminares sobre novos dilemas políticos. Novos Estudos Cebrap, v. 31, p. 131-141, 1991.

RIGAKOS, G. S.; GREENER, D. R. Bubbles of governance: private policing and the law in Canada. Canadian Journal of Law and Society / La Revue Canadienne Droit et Société, v. 15, n. 1, p. 145-185, Abr. 2000. 
RODRIGUES, R.; RIBEIRO, E.; CANO, I. A privatização da segurança no Brasil e no Rio de Janeiro: tamanho, evolução e precarização da segurança privada. Trabalho completo apresentado no Simpósio Mercados de Proteção e Governança da Segurança. Londrina, 2019. Disponível em: <http://www2.uel.br/laboratorios/legs/ wp-content/uploads/2019/06/GT1_RobsonRodrigues.pdf>.

SARRE, R. Legal sources of private security powers. Canberra Law Review, v. 7, p. 109, 2003.

SHEARING, C. D. A relação entre policiamento público e policiamento privado. In: TONRY, M.; MORRIS, N. (Eds.). Policiamento moderno, p. 427-462. São Paulo: Edusp, 2003.

SHEARING, C. D.; STENNING, P. C. Private security: implications for social control. Social problems, p. 493-506, 1983.

Modern private security: its growth and implications. Crime and Justice, v. 3, p. 193-245, Jan. 1981.

SHEARING, C.; WOOD, J. Nodal governance, democracy, and the new "denizens". Journal of Law and Society, v. 30, n. 3, p. 400-419, 2003.

SILVA LOPES, C.da. A. Policing labor: the power of private security guards to search workers in Brazil. Crime, Law and Social Change, v. 70, n. 5, p. 583-602, Dez. 2018.

STENNING, P. C. Powers and accountability of private police. European Journal on Criminal Policy and Research, v. 8, n. 3, p. 325-352, Set. 2000.

STENNING, P. C.; SHEARING, C. D. Search and seizure - powers of private security personnel. Canada: Law Reform Commission of Canada, 1979.

WAKEFIELD, A. Selling security. London; New York: Routledge, 2003.

ZANETIC, A. Policiamento e segurança privada: duas notas conceituais. Estudos de Sociologia, v. 17, n. 33, 2012. 